\title{
GLYCOSAMINOGLYCAN DISTRIBUTION IN THE RAT UTERINE CERVIX DURING THE ESTROUS CYCLE
}

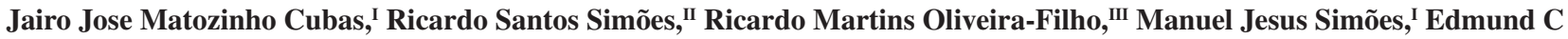 \\ Baracat, ${ }^{\mathrm{II}}$ José Maria Soares-Jr ${ }^{\mathrm{IV}}$
}

doi: $10.1590 / \mathrm{S} 1807-59322010000700009$

Cubas JJM, Simões RS, Oliveira-Filho R M, Simões MJ, Baracat EC, Soares-Jr JM. Glycosaminoglycan distribution in the rat uterine cervix during the estrous cycle. Clinics. 2010;65(7):703-8.

OBJECTIVE: To analyze the amount of glycosaminoglycans in the uterine cervix during each phase of the rat estrous cycle. DESIGN: Based on vaginal smears, forty female, regularly cycling rats were divided into four groups ( $\mathrm{n}=10$ for each group): GI - proestrous, GII - estrous, GIII - metaestrous and GIV - diestrous. Animals were sacrificed at each phase of the cycle, and the cervix was immediately removed and submitted to biochemical extraction and determination of sulfated glycosaminoglycans and hyaluronic acid. The results were analyzed by ANOVA followed by the Bonferroni post-hoc test.

RESULTS: The uterine cervix had the highest amount of total sulfated glycosaminoglycans and dermatan sulfate during the estrous phase $(8.90 \pm 0.55 \mathrm{mg} / \mathrm{g}$ of cetonic extract, $\mathrm{p}<0.001$; and $8.86 \pm 0.57 \mathrm{mg} / \mathrm{g}$ of cetonic extract, $\mathrm{p}<0.001)$. In addition, there was more heparan sulfate at the cervix during the proestrous phase $(0.185 \pm 0.03 \mathrm{mg} / \mathrm{g}$ of cetonic extract $)$ than during any other phase $(\mathrm{p}<0.001)$. There were no significant changes in the concentration of hyaluronic acid in the uterine cervix during the estrous cycle. CONCLUSION: Our data suggest that the amount of total sulfated glycosaminoglycans may be influenced by hormonal fluctuations related to the estrous cycle, with dermatan sulfate and heparan sulfate being the glycosaminoglycans most sensitive to hormonal change.

KEYWORDS: Heparan sulfate; Dermatan sulfate; Hyaluronic acid; Cervix uteri; Estrous cycle.

\section{INTRODUCTION}

Much clinical interest has been focused on glycosaminoglycans (GAGs) in all fields of medicine, as these molecules are related to cell recognition, migration, proliferation and differentiation. In addition, they are directly and indirectly involved with the tumorigenesis, metastasis, angiogenesis, immune responses, follicular development,

\footnotetext{
I Departmento de Morfologia e Genética, Universidade Federal de São Paulo - São Paulo/SP, Brazil.

II Departamento de Obstetrícia e Ginecologia, Faculdade de Medicina, Universidade de São Paulo - São Paulo/SP, Brazil.

III Department of Pharmacology, Instituto de Ciências Biomédicas, Universidade de São Paulo - São Paulo/ SP, Brazil.

IV Department of Gynecology, Escola Paulista de Medicina - São Paulo/ SP, Brazil.

Email: manuel.morf@epm.br

Tel.: $55115576-4268$

Received for publication on January 19, 2010

First review completed on February 19, 2010

Accepted for publication on April 09, 2010
}

embryo implantation, spermatozoa capacitation and infertility. ${ }^{1-4}$

The extracellular matrix is a network of aggregates made up of a molecular nest containing collagen, glycoproteins, proteoglycans and GAG polysaccharide side chains. This nest maintain the cell's structure, thus allowing organization of cells into tissues and ultimately permitting cell survival. ${ }^{5}$ GAGs are also involved in various tissue functions, such as the hydration of the spaces surrounding cells, the formation of gels of various sizes and charge densities and the regulation of the passage of molecules to the extracellular environment. GAGs serve as binding sites for growth factors and other cell signaling proteins, which in turn function to block, activate or guide cell migration through the matrix. ${ }^{6} \mathrm{In}$ fact, spermatozoa capacitation may be related to the binding of GAGs on the cell membrane of the sperm located in the cervix. $^{4}$

Several authors have evaluated the human endometrium during the reproductive ages, during pregnancy and after 
menopause, finding that the sulfated GAGs of this tissue were comprised of heparan sulfate (HS), dermatan sulfate (DS) and chondroitin sulfate (CS), as well as hyaluronic acid (HA). ${ }^{3,7,8}$ However, not much variation was found in the concentrations of these GAGs through the different phases of reproductive life, with the exception of a significant reduction of GAGs during gestation and a rise in CS among women with leiomyoma and leiomyosarcoma. ${ }^{3,8}$ Other investigators found that the concentration of HA in the endometrial stroma peaked during human embryo implantation..$^{9,10}$ Indeed, in vitro studies in both human and animal models have demonstrated the relevance of HA and its receptors in the process of implantation. ${ }^{11}$ Additionally, Gomes et al. ${ }^{12}$ identified DS, HS and CS in the murine uterine horns during all phases of the estrous cycle, with higher concentrations of DS and CS during estrous (estrogenic action) and of HS during diestrous (progestagenic action). However, Teixeira-Gomes et al. found that in a murine model, HA was more concentrated in the diestrous phase. ${ }^{13}$ Although these findings suggest a variation in uterine glycosaminoglycans during the estrous phase, specific knowledge concerning the concentration of these substances in the uterine cervix is scarce. Therefore, our study aimed to analyze the concentration of GAGs in the rat uterine cervix during each estrous cycle phase.

\section{MATERIAL AND METHODS}

Wistar female rats (Rattus norvegicus albinus) with an average body weight of approximately $250 \mathrm{~g}$ were used throughout the study. The rats were obtained from the Center for the Development of Experimental Models (CEDEME) of the Federal University of São Paulo - Escola Paulista de Medicina (UNIFESP-EPM). Experiments were approved (Report No. 0809/04) by the local Animal Care Committee, following guidelines complying with those of the Canadian Council on Animal Care. ${ }^{14}$

The animals ( $\mathrm{n}=10$ per cage) were kept with food and water ad libitum at room temperature $\left(22{ }^{\circ} \mathrm{C}\right)$ with artificial light provided by fluorescent Phillips lamps (daylight model, $40 \mathrm{~W}$ ) with a photoperiod of $12 \mathrm{~h}$ (lights on 07:00-19:00 h).

After a one-week adaptation period to the new environment, daily vaginal smears were taken for eight consecutive days to determine the periodicity of the estrous cycle. Based on the colpocytologic results, the animals were then divided into four groups of ten animals each: GI - proestrous; GII - estrous; GIII - metaestrous and GIV diestrous.

The rats were anesthetized (xylazine $20 \mathrm{mg} / \mathrm{kg}$ plus ketamine $100 \mathrm{mg} / \mathrm{kg}$, i.p.), and the female genital tract was dissected out. The uterine cervix was immediately removed and put into acetone for further biochemical analyses.

\section{Characterization and quantification of the sulfated glycosaminoglycans (GAGs)}

The biochemical analyses for characterization and quantification of the sulfated GAGs were carried out at the Molecular Biology Division of the Department of Biochemistry of the Universidade Federal de São Paulo Escola Paulista de Medicina (UNIFESP - EPM).

The identification of each GAG was done using the following standards: chondroitin-4-sulfate from whale cartilage, chondroitin-6-sulfate from shark cartilage, dermatan sulfate from bovine intestinal mucosa (Seikagaku Kogyo Co., Tokyo, Japan) and heparan sulfate from bovine lung (extracted and purified by the Molecular Biology Division of the Department of Biochemistry of UNIFESP - EPM). ${ }^{15}$

To improve the identification of GAGs, controls were generated by enzymatic degradation of the sulfated GAGs by $F$. heparinum-derived chondroitinases. Dermatan sulfate and chondroitin sulfate were characterized after incubation of the samples with chondroitinase AC and chondroitinase ABC.

The incubation products were submitted to agarose gel electrophoresis, and the confirmation of the particular type of GAG was accomplished by the distinct band pattern in the agarose gel.

The same standards were also used for quantitative determination of the samples by $525 \mathrm{~nm}$ densitometry. The results were expressed as $\mu \mathrm{g}$ of GAG per $\mathrm{mg}$ of cetonic extract, powder (mean \pm SEM). All samples were assayed in triplicate. The detection limit was $1 \mu \mathrm{g} / \mu \mathrm{L}$ of GAG sulfate.

\section{Extraction and quantification of hyaluronic acid (HA)}

Determination of HA was performed using a highly specific, highly sensitive "ELISA-like" fluorimetric method that employed a biotinylated HA-binding protein and europium-labeled streptavidin. ${ }^{16}$ The detection limit of this method is ca. $0.2-500 \mathrm{ng} / \mathrm{ml}$ of HA. ${ }^{16}$ The samples were assayed in triplicate. The plates were read in a Victor 2-Wallac Ou (Turku, Finland) fluorimeter.

\section{Hormonal determination}

Serum estrogen and progesterone levels were assayed in triplicate. Estrogen (ACS -180 Bayer, detection limit 10 pg/ $\mathrm{ml}$ ) and progesterone (ACS- 180 Bayer, detection limit 0.1 $\mathrm{ng} / \mathrm{ml}$ ) were measured by chemiluminescence with Centaur Bayer equipment (Bayer, Walpole, USA). Cross-reactivity with other steroids was $<0.01 \%$. 


\section{Statistical analysis}

Data were expressed as the mean, median and SEM and were then examined for sample homogeneity using Bartlett's test. When appropriate, the analysis of variance test (ANOVA) was performed, followed by Bonferroni's post-hoc test, using SigmaStat 2.03 (SSI, Point Richmond, CA) software. The significance level (alpha) was set at 5\%.

\section{RESULTS}

Hyaluronic acid and the sulfated glycosaminoglycans dermatan sulfate (DS) and heparan sulfate (HS) were identified in the uterine cervix of rats during all phases of the estrous cycle. As shown in Table 1, the highest total sulfated glycosaminoglycan concentration in the rat uterine cervix was found during the estrous phase $(8.90 \pm 0.55 \mathrm{mg} / \mathrm{g}$ of cetonic extract, $P<0.001)$. The cervical concentration of dermatan sulfate ranged from about 3.7 to $8.9 \mathrm{mg} / \mathrm{g}$ of cetonic extract. The highest values were detected during the estrous phase $(8.86 \pm 0.57 \mathrm{mg} / \mathrm{g}$ of cetonic extract, $P<0.001)$. The heparan sulfate (HS) ranged from about 0.02 up to $0.19 \mathrm{mg} / \mathrm{g}$ of cetonic extract. The highest among of HS was found during proestrous phase $(0.185 \pm 0.03 \mu \mathrm{g} / \mathrm{g}$ of cetonic extract, $P<0.001)$. The electrophoretic pattern of GAGs in the rat uterine cervix is shown in Figure 1. We did not detect chondroitin-4-sulfate (4-CS), chondroitin-6-sulfate (6-CS) or keratan sulfate $(\mathrm{KS})$.

As shown in Table 1, DS was the main contributor to the total sulfated GAGs in the rat uterine cervix, reaching its maximal concentration at the estrous phase. During this phase, the level of DS was at its maximum while the levels of HS were at their lowest, giving rise to a DS/HS ratio of nearly 260:1. There was no significant change in the concentration of hyaluronic acid in the uterine cervix during the rat estrous cycle.

\section{Serum ovarian hormones}

High levels of estradiol were detected during the proestrous phase $(29.56 \pm 0.03 \mathrm{pg} / \mathrm{mL}, \mathrm{p}<0.001)$, while high levels of progesterone were evident during both the proestrous and metaestrous phases. Table 1 shows the values of estradiol.

\section{DISCUSSION}

The glycosaminoglycans (GAGs) in human cervical tissue consist of sulfated GAGs and hyaluronic acid (HA). ${ }^{17,18}$ The sulfated GAGs are primarily present in the form of small leucine-rich proteoglycans (SLRPs) such as decorin and biglycan. The SLRPs contain specific collagen-binding sites and contribute to the organization of the collagen network. Multiple studies have demonstrated a change in glycosaminoglycan concentrations during pregnancy. ${ }^{9}$ Shimizu et al. ${ }^{19}$ found that the contents of hyaluronic acid, chondroitin sulfate, heparan sulfate and acidic glycosaminoglycan increased in the postpartum cervix compared to the non-pregnant cervix. Dermatan sulfate (primarily associated with decorin) was the only GAG that was found to decrease with cervical remodeling. Osmers ${ }^{20}$ reported an increase in total GAGs during pregnancy but a large decrease in dermatan sulfate at the time of parturition. The changes in proteoglycan content were found to occur primarily with the onset of labor. In particular, the decrease in dermatan sulfate and increase in HA are believed to

Table 1 - Concentrations of glycosaminoglycans (GAGs) extracted from uterine cervices of rats in different phases of the estrous cycle (mean \pm SEM).

\begin{tabular}{|c|c|c|c|c|}
\hline & \multicolumn{4}{|c|}{ Estrous cycle phase } \\
\hline & Proestrous & Estrous & Metaestrous & Diestrous \\
\hline \multicolumn{5}{|l|}{ Sulfated GAGs } \\
\hline Dermatan sulfate (mg/g of cetonic extract) & $4.55 \pm 0.72$ & $8.86 \pm 0.57 *$ & $3.74 \pm 0.89$ & $4.70 \pm 1.37$ \\
\hline Heparan sulfate (mg/g of cetonic extract) & $0.185 \pm 0.03^{*}$ & $0.033 \pm 0.049$ & $0.032 \pm 0.025$ & $0.025 \pm 0.026$ \\
\hline Total sulfated GAGs (mg/g of cetonic extract) & $4.74 \pm 0.75$ & $8.90 \pm 0.55^{*}$ & $3.77 \pm 0.88$ & $4.73 \pm 1.33$ \\
\hline DS/HS ratio & $24.6 \pm 4.24$ & $268.5 \pm 8.23 *$ & $116.9 \pm 1.06$ & $188.0 \pm 5.87$ \\
\hline \multicolumn{5}{|l|}{ Carboxylated GAG } \\
\hline Hyaluronic acid (mg/g) & $9.44 \pm 2.98$ & $7.16 \pm 1.53$ & $10.92 \pm 3.58$ & $16.77 \pm 11.92$ \\
\hline \multicolumn{5}{|l|}{ Sex steroid levels } \\
\hline Estradiol (pg/mL) & $35.56 \pm 0.03^{*}$ & $12.21 \pm 0.09$ & $16.34 \pm 0.11$ & $21.19 \pm 0.04$ \\
\hline Progesterone $(\mathrm{ng} / \mathrm{mL})$ & $12.67 \pm 0.23 * *$ & $3.34 \pm 0.45$ & $9.89 \pm 0.19 * *$ & $5.29 \pm 0.33$ \\
\hline
\end{tabular}

$* P<0.001$ compared to other groups. $\mathrm{DS}=$ dermatan sulfate; $\mathrm{HS}=$ heparan sulfate $* * P<0.001$ compared to the estrous or the diestrous phase 


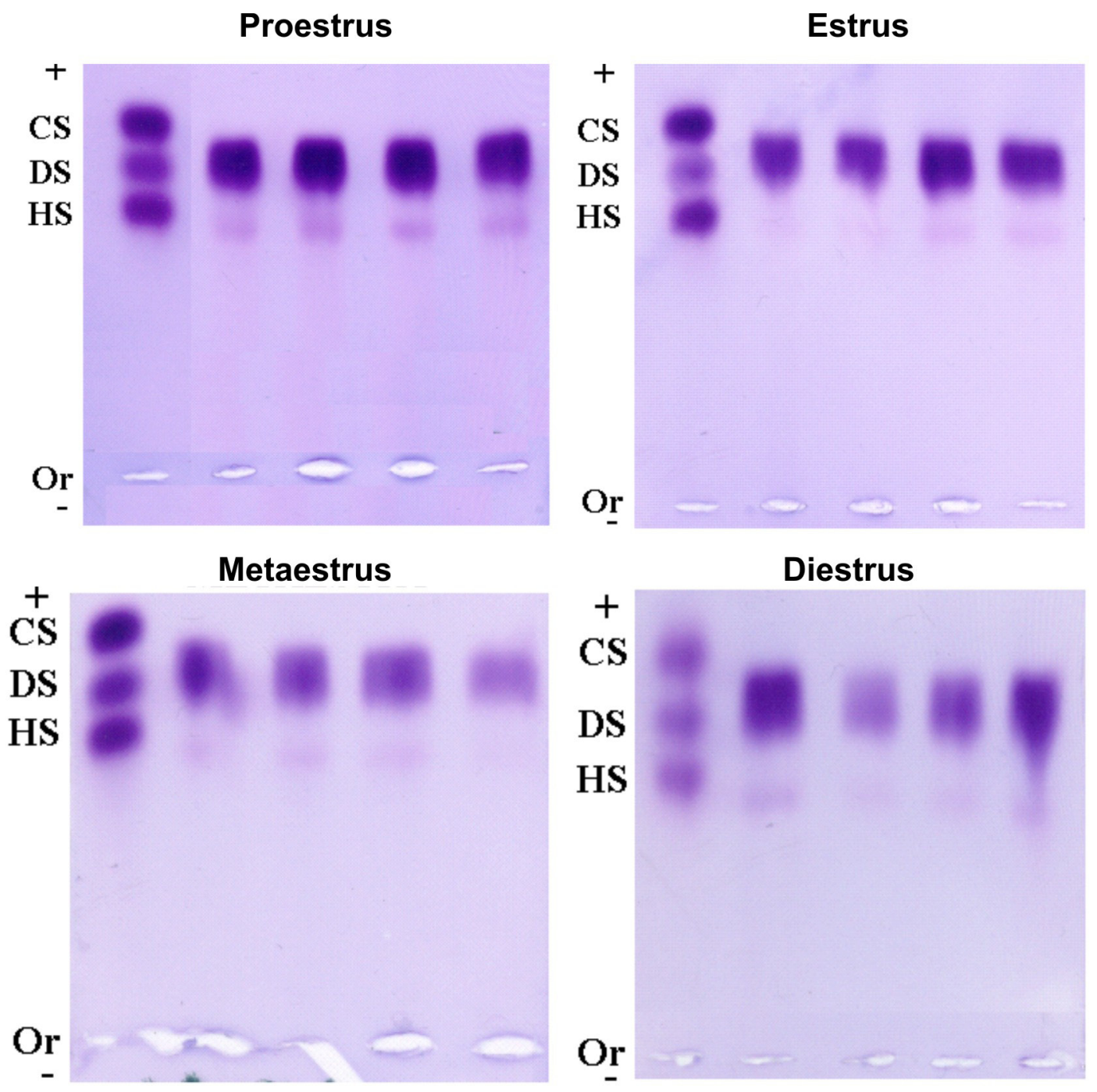

Figure 1 - Typical electrophoretic pattern of sulfated glycosaminoglycans of the rat uterine cervix at each phase of the estrous cycle. Legends: CS = chondroitin sulfate; DS = dermatan sulfate; HS = heparan sulfate; Or = origin (at the negative pole).

play a fundamental role in the disruption of the collagen network. $^{21,22}$

In the rat uterine cervix, we detected HA, DS and HS during all phases of the estrous cycle; we did not detect 4-CS, 6-CS or KS. However, Kofoed et al. ${ }^{23,24}$ and Cidadão et al. ${ }^{25}$ reported 4- and 6-CS in the corpus of the uterus of prepubertal rats treated with estrogens and/or progestagens. In contrast, Simões et al. ${ }^{26}$ did not find $4-\mathrm{CS}$ or $6-\mathrm{CS}$ in the uterine horns of adult rats that had been ovariectomized $(\mathrm{OVx})$ or treated with estrogens and/or progestagens. This finding was ascribed to factors such as the particular animal age or the time elapsed after OVx, which may have influenced the rat uterine metabolism of GAGs. In our study, we found high values for the DS/HS ratio during the estrous phase. It is important to emphasize that DS is the primary GAG associated with high levels of collagen. Additionally, this GAG may play a role in the organization of collagen in the uterine cervix. ${ }^{27}$ The fact that DS is critical for the organization of collagen is related to the decrease in ECM in mice, because there is less HS to form the water-retaining ECM. ${ }^{27}$ Changes in GAGs may reflect the quality of the cervical mucus. In fact, alterations in DS/HS ratios may be responsible for the modification of cervical mucus barrier properties ${ }^{28}$ which may in turn affect the ascension of spermatozoids and microbial infections.

HS is displayed on the outer side of the cell membrane, maintaining cell hydration in addition to binding to proteins of the matrix and to growth factors. In addition, HS may associate with a membrane protein to form a proteoglycan called sindecan, which is involved in cell signaling through interaction with integrins and tyrosine kinase receptors that are, in turn, associated with cell replication. ${ }^{2,29}$ It is 
likely that the increase in HS facilitates the ascension of spermatozoids during the proestrous phase.

With respect to the reproductive capability of mice during the estrous cycle, the quality of cervical mucus, which is dependent on glycosaminoglycan composition, may facilitate or block spermatozoid ascension. In women, cervical mucus contains hyaluronic acid (3\%), HS (2\%) and DS (13\%) during the secretory phase. This composition may reduce the water content in the mucus, which tends to be denser than the mucus in the first phase of menstrual cycle; ${ }^{30}$ such a change may underlie the changes we saw in our experiment. This possibility will be explored in future works.

The concentration of GAGs during the proestrous phase may respond to changes in the hormonal environment. It is conceivable that the synthesis of sulfated GAGs could be stimulated by estrogens but not by progestagens..$^{23,26}$ However, the concerted action of both hormones could increase the tissue concentrations of GAGs, as our findings indicate.

In rats treated for 30 days with progesterone plus estrogens, the production of HS was inhibited in the corpus of the uterus, but treatment with estrogens alone caused stimulation. ${ }^{31}$ These data are somewhat paralleled by the present findings, as during metaestrous and at the beginning of proestrous, there was a rise in the circulating levels of progesterone and at the end of proestrous there was a peak in estrogens. ${ }^{32}$ This hormonal change during the estrous cycle may influence the concentration of GAGs in the murine uterine cervix. In fact, high levels of estrogen and progesterone are related to the high amounts of HS in the murine cervix, as our data show. It is important to emphasize that HS is the primary binding factor for most types of HPV. ${ }^{33}$ Therefore, though our findings appear to be clinically relevant, further studies are necessary to specifically investigate the relationship between contraceptive hormones and the amount of HS in the human uterine cervix as well as the HPV infection with the HS distribution during the menstrual cycle.

\section{CONCLUSIONS}

The concentration of the glycosaminoglycans (GAGs) of the cellular matrix in the rat uterine cervix varies during the phases of the estrous cycle; dermatan sulfate is the prominent GAG in the estrous phase, whereas heparan sulfate prevails in the proestrous phase. Overall, our results suggest that hormonal fluctuation related to the estrous phase may affect the rat uterine cervix via effects on the production of heparan sulfate and dermatan sulfate.

\section{REFERENCES}

1. Dutt S, Matasci M, Sommer L, Zimmermann DR. Guidance of neural crest cell migration: the inhibitory function of the chondroitin sulfate proteoglycan, versican. Scientific World Journal. 2006;6:1114-7.

2. Lopes CC, Dietrich CP, Nader HB. Specific structural features of syndecans and heparan sulfate chains are needed for cell signaling. Braz J Med Biol Res. 2006;39:157-67.

3. Nasciutti LE, Ferrari R, Berardo PT, Souza ML, Takiya CM, Borojevic $\mathrm{R}$, et al. Distribution of chondroitin sulfate in human endometrium. Mícron. 2006;37:544-50.

4. Griffiths GS, Miller KA, Galileo DS, Martin-DeLeon PA. Murine SPAM1 is secreted by the estrous uterus and oviduct in a form that can bind to sperm during capacitation: acquisition enhances hyaluronic acid-binding ability and cumulus dispersal efficiency. Reproduction. 2008;135:293-301.

5. Bulow HE, Hobert O. The molecular diversity of glycosaminoglycans shapes animal development. Annu Rev Cell Dev Biol. 2006;22:375-407.

6. Kresse H, Schönher E. Proteoglycans of the extracellular matrix and growth control. J Cell Physiol. 2001;189:266-74.

7. Loewi G, Consden R. Acid mucopolysaccharides of the human uterus. Nature. 1962; 195:148-50.

8. Chen MJ, Peng Y, Yang YS, Huang SC, Chow SN, Torng PL. Increased hyaluronan and CD44 expressions in intravenous leiomyomatosis. Acta Obstet Gynecol Scand. 2005; 84:322-8.
9. Toole BP, Wight TN, Tammi MI. Hyaluronan-cell interactions in cancer and vascular disease. J Biol Chem. 2002;277:4593-6.

10. Salamonsen LA, Shuster S, Stern R. Distribution of hyaluronan in human endometrium across the menstrual cycle. Implications for implantation and menstruation. Cell Tissue Res. 2001;306:335-40.

11. Aplin JD. The cell biological basis of human implantation. Baillieres Best Pract Res Clin Obstet Gynaecol. 2000;14:757-64.

12. Gomes RCT, Oliveira-Filho RM, Simões MJ, Soares Jr JM, Nader HB. Perfil de glicosaminoglicanos sulfatados no útero de camundongas durante o ciclo estral. Rev Bras Med. 2007;53:261-6.

13. Teixeira-Gomes RC, Verna C, Nader HB, Simões RS, Dreyfuss JL, Martins JRM, et al. Concentration and distribution of hyaluronic acid in mouse uterus throughout the estrous cycle. Fertil Steril. 2009;92:785-92.

14. Olfert ED, Cross BM, McWilliam AA (editors). Canadian Council on Animal Care's/ Guide to the Care and Use of Experimental Animals. 2nd ed. Ottawa, Canada: Bradda Printing Services, 1993.

15. Aguiar JAK, Lima CR, Berto AGA, Michelacci YM. An improved methodology to produce Flavobacterium heparinum condroitinases, important instruments for diagnosis of diseases. Biotechnol Appl Biochem. 2003; 37:115-27.

16. Martins JR, Passerotti CC, Maciel RM, Sampaio LO, Dietrich CP, Nader HB. Practical determination of hyaluronan by a new noncompetitive fluorescence-based assay on serum of normal and cirrhotic patients. Anal Biochem. 2003;319:65-72. 
17. Myers KM, Paskaleva AP, House M, Socrate S. Mechanical and biochemical properties of human cervical tissue. Acta Biomater. 2008;4:104-16.

18. Myers K, Socrate S, Tzeranis D, House M. Changes in the biochemical constituents and morphologic appearance of the human cervical stroma during pregnancy. Eur J Obstet Gynecol Reprod Biol. 2009;144(1 Suppl):82S-9S

19. Shimizu T, Endo M, Yosizawa Z. Glycoconjugates (glycosaminoglycans and glycoproteins) and glycogen in the human cervix uteri, Tohoku J Exp Med. 1980;131:289-99.

20. Osmers RG, Adelmann-Grill BC, Rath W, Stuhlsatz HW, Tschesche $\mathrm{H}$, Kuhn W. Biochemical events in cervical ripening dilatation during pregnancy and parturition. J Obstet Gynaecol. 1995;21:185-94.

21. El Maradny E, Kanayama N, Kobayashi H, Hossain B, Khatun S, Liping $\mathrm{S}$, et al. The role of hyaluronic acid as a mediator and regulator of cervical ripening. Hum Reprod. 1997;12:1080-8.

22. Lopes VA, Luz MR, Souza GN, Fernandes Júnior JA, Simões MJ, Camano L, et al. Histochemical changes of the glycosaminoglycans in the uterine cervix of pregnant rats after local injection of hyaluronidase. Rev Bras Ginecol Obstet. 2008; 30:328-34.

23. Kofoed JA, Houssay AB, Tocci AA, Curbelo HM. Effects of oestrogens upon glycosaminoglycans in the uterus of rats. Acta Endocrinol. 1972;69:87-94.

24. Kofoed JA, Houssay AB, Tocci AA, Curbelo HM, Barcelo C. Effects of acetoxyprogesterone upon glycosaminoglycans in the uterus and salivary glands of rats. Horm Metab Res. 1977;9:58-9.

25. Cidadão AJ, Thorsteinsdottir S, Ferreira DJF. Immunocytochemical study of tissue distribution and hormonal control of chondroitim, dermatan and keratan sulfate from rodent uterus. Eur J Cell Biol. 1990;52:105-16.
26. Simoes MJ, Simões RS, Nader HB, Soares Jr JM, Baracat EC. Histomorphological analysis and characterization of glycosaminoglycans of adult castrated rat uteri treated with estrogen, progestogen and raloxifene. Climateric. 2002;5:144.

27. Greca CD, Nader HB, Dietrich CP, Abrahamsohn PA, Zorn TM. Ultrastructural cytochemical characterization of collagen-associated proteoglycans in the endometrium of mice. Anat Rec. 2000;259:413-23.

28. Domino SE, Hurd EA. LacZ expression in Fut2-LacZ reporter mice reveals estrogen-regulated endocervical glandular expression during estrous cycle, hormone replacement, and pregnancy. Glycobiology. 2004; 14:169-75.

29. Moreira CR, Lopes CC, Cuccovia IM, Porcionatto MA, Dietrich CP, Nader HB. Heparan sulfate and control of endothelial cell proliferation: increased synthesis during the $\mathrm{S}$ phase of the cell cycle and inhibition of thymidine incorporation induced by ortho-nitrophenyl-beta-D-xylose. Biochim Biophys Acta. 2004;1673:178-85.

30. Uldbjerg N, Carlstedt I, Ekman G, Malmström A, Ulmsten U, Wingerup L. Dermatan sulphate and mucin glycopeptides from the human uterine cervix. Gynecol Obstet Invest. 1983;16:199-209.

31. Carson DD, Tang JP, Julian J, Glasser SR. Vectorial secretion of proteoglycans by polarized rat uterine epithelial cells. J Cell Biol. 1988; 107:2425-35.

32. Tebar M, Ruiz A, Gaytan F, Sanchez-Criado JE. Follicular and luteal progesterone play different roles synchronizing pituitary and ovarian events in the 4-day cyclic rat. Biol Reprod. 1995;53:1183-9.

33. Johnson KM, Kines RC, Roberts JN, Lowy DR, Schiller JT, Day PM. Role of heparan sulfate in attachment to and infection of the murine female genital tract by human papillomavirus. J Virol. 2009;83:2067-74. 